\title{
Presumed consent: yes we should
}

W hen one would-be attendee at Barack Obama's acceptance speech for the Democratic presidential candidate nomination realized shortly before the ceremony in Denver on 28 August 2008 that his application for tickets had been unsuccessful, he posted a last-minute advertisement online: "Are you in need of an extra kidney? Know of someone who needs one? I have two good kidneys, which is a little excessive. I'll give you one of them for two tickets to tonight's speech."

At least one supporter of President Obama is clearly an enthusiastic advocate of organ donation, but the views of Obama himself on this issue are unknown. By contrast, UK Prime Minister Gordon Brown has set out his stance in favor of an 'opt-out' or 'presumed consent' system of organ donation. Writing in the Sunday Telegraph in January 2008, he commented "A system of this kind seems to have the potential to close the aching gap between the potential benefits of transplant surgery in the UK and the limits imposed by our current system of consent."

To Brown's dismay, and that of the British Medical Association, a government-appointed task force subsequently rejected the introduction of opt-out organ donation in the UK. However, a systematic review published in the British Medical Journal almost exactly 1 year after Brown's editorial seems to bear out the promise of presumed consent (Rithalia, A. et al. BMJ 338, a3162 [2009]). In their review of studies conducted in five countries, the authors found that rates of organ donation increased consistently and markedly after the introduction of presumed consent. Cautiously, they note that the contribution of other factors to these increases cannot be excluded.

In a system of presumed consent, everyone is considered to be a potential organ donor at death, unless they have previously registered an explicit wish to the contrary. Opt-out systems are generally classed as either 'hard' or 'soft'. A 'soft' system, such as that which operates in Spain, takes into consideration the next of kin's knowledge that the deceased had an unregistered objection or the fact that donation would cause severe distress to relatives. In a 'hard' system, such as that practiced in Austria, relatives' views are not sought. Opt-out systems aim to foster a perception of donation as the norm rather than the exception.

Opponents of presumed consent often argue that such a system removes choice from donors and gives the state rights over people's bodies after death. They point to the fact that Brazil was forced to repeal its presumed consent law after only 1 year, following accusations of body snatching. Some health-care professionals are concerned that presumed consent could erode patients' trust that doctors are acting in their best interests, which might dissuade potential donors. However, these concerns are not borne out in reality and they pale in comparison to the potential benefits. Families would no longer face the terrible uncertainty of trying to guess a deceased relative's wishes while coping with their own grief, or have to deal with subsequent feelings of guilt at making the 'wrong' decision. Individuals who wish to opt out of donation are highly likely to register their choice and thereby ensure that it will be respected, while individuals who do wish to donate don't have to make any effort to ensure that their gift is given.

The disparity between the trickle of donated kidneys and the desperate thirst for these life-saving organs grows every day. Surveys suggest that the majority of people simply haven't got around to registering as donors rather than having active objections to donation. Presumed consent is in no way a cure-all for the mismatch between the supply and demand for donor kidneys; however, introducing such a system in the US, the UK and other countries where it is feasible would reduce the numbers of people who die from kidney failure while others are buried or cremated with healthy kidneys that they would have happily donated. Two kidneys may not be "excessive" during life, but they surely are after death.

doi:10.1038/nrneph.2009.47

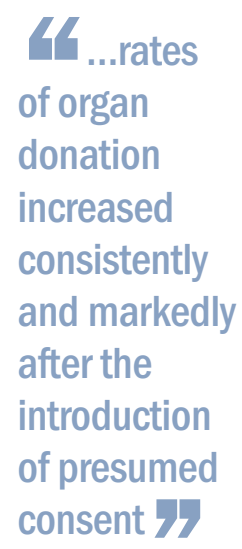

Chloë Harman is the Editor of Nature Reviews Nephrology.

Competing interests The author declared no competing interests. 